\title{
Characterization of Mechanically Alloyed Nanocrystalline Fe(Al): Crystallite Size and Dislocation Density
}

\author{
M. Mhadhbi, ${ }^{1}$ M. Khitouni, ${ }^{1}$ L. Escoda, ${ }^{2}$ J. J. Suñol, ${ }^{2}$ and M. Dammak ${ }^{1}$ \\ ${ }^{1}$ Laboratoire de Chimie Inorganique, Faculté des Sciences de Sfax, Université de Sfax, B.P. 1171, Sfax 3018, Tunisia \\ ${ }^{2}$ Departamento de Física, Universitat de Girona, Campus Montilivi, 17071 Girona, Spain \\ Correspondence should be addressed to M. Khitouni, khitouni@yahoo.fr
}

Received 24 March 2010; Revised 19 July 2010; Accepted 15 November 2010

Academic Editor: Edward Andrew Payzant

Copyright (C) 2010 M. Mhadhbi et al. This is an open access article distributed under the Creative Commons Attribution License, which permits unrestricted use, distribution, and reproduction in any medium, provided the original work is properly cited.

\begin{abstract}
A nanostructured disordered $\mathrm{Fe}(\mathrm{Al})$ solid solution was obtained from elemental powders of $\mathrm{Fe}$ and $\mathrm{Al}$ using a high-energy ball mill. The transformations occurring in the material during milling were studied with the use of X-ray diffraction. In addition lattice microstrain, average crystallite size, dislocation density, and the lattice parameter were determined. Scanning electron microscopy (SEM) was employed to examine the morphology of the samples as a function of milling times. Thermal behaviour of the milled powders was examined by differential scanning calorimetry (DSC). The results, as well as dissimilarity between calorimetric curves of the powders after 2 and $20 \mathrm{~h}$ of milling, indicated the formation of a nanostructured $\mathrm{Fe}(\mathrm{Al})$ solid solution.
\end{abstract}

\section{Introduction}

Mechanical alloying (MA) is a technique commonly used to obtain supersaturated solid solutions, compounds with high energy of mixing, and alloys of combinations of elements which do not show appreciable solubility in their equilibrium phase diagrams [1-3]. The Fe-Al system is an example of a binary system with a low solid miscibility at room temperature; however, by means of $\mathrm{MA} \mathrm{Fe}(\mathrm{Al})$ solid solutions have been obtained in almost all the compositional range. In recent years, a number of studies have been reported on mechanical alloying of FeAl. It is established that the formation of the supersaturated solid solution (SSS) $\alpha$ $\mathrm{Fe}(\mathrm{Al})$ as a final product of MA takes place with $x \leq 60$ at $\% \mathrm{Al}$ though in a number of papers the formation of SSS was found with $x=75$ at \% Al [4-9]. For instance, Zeng and Baker [9] investigated the effect of milling time on the crystallite size, lattice strain, and lattice parameter of $\mathrm{Fe}$ 40 at $\% \mathrm{Al}$ powder mixture. According to their results, the crystallite size is less than $7 \mathrm{~nm}$ after $4 \mathrm{~h}$, indicating a rapid decrease of size, but milling for more than $6 \mathrm{~h}$ results in some increase in the nanocrystalline size. They attributed this fact to the dynamic recrystallization and/or nanocrystalline grain growth. The same results were shown in the case of
$\mathrm{MA} \mathrm{Fe}-45$ at \% Al [10]. Moreover, the lattice parameter also increased at first up to $10 \mathrm{~h}$ milling, then decreased. This decrease has attributed to the oxidation during milling, which decreases the $\mathrm{Al}$ content. In addition, Wolski et al. [11] studied the effect of milling conditions on the Fe35 at \% $\mathrm{Al}$ intermetallic formation by MA. According to their investigation, this process occurred in two steps: a nanocrystallization step and an FeAl formation step. FeAl formation started rapidly by the creation of Al-rich and Ferich solid solutions; the latter became dominant after long milling times and tended to the composition $\mathrm{Fe}-35$ at \% Al. Haghighi et al. [12] investigated the structural evolution of nanocrystalline $\mathrm{Fe}-50$ at \% $\mathrm{Al}$ compound during MA. As their results showed, with increasing the milling time, the lattice parameter of the $\mathrm{Fe}(\mathrm{Al})$ phase increased due to the solution of $\mathrm{Al}$ atoms in Fe lattice and reached a steady value after $80 \mathrm{~h}$ of milling. The crystallite size and lattice strain of the $\mathrm{Fe}(\mathrm{Al})$ solid solution increased to $50 \mathrm{~h}$ of $\mathrm{MA}$, then decreased between 50 and $80 \mathrm{~h}$ and remained nearly constant to $100 \mathrm{~h}$. On the other hand, Krasnowski et al. [13] investigated the effect of milling time on the microstructure evolution of the same alloy and showed that the lattice parameter increased, but the crystallite size and lattice strain increased up to $6 \mathrm{~h}$ and then decreased and finally after $10 \mathrm{~h}$ 
remained constant. In all powders studied, these authors found that the grain size of $\mathrm{BCC} \mathrm{Fe}(\mathrm{Al})$ solid solution was in the nanometer range and the lattice strain increased with milling time. These variations of structural parameters may be understood in terms of the various deformation and annealing mechanisms occurring and the way these create or eliminate defects within the solid solution and/or the intermetallic $[14,15]$. During milling, initial deformation leads to the accumulation of a high dislocation density, with many antiphase boundaries (APBs) as the dislocations become dissociated into partial dislocations, followed by the rearrangement of the dislocations into cell walls, subgrain boundaries, and later into grain boundaries. In this way a fine grain size is quickly introduced, with the extent of internal strain determined by the remnant dislocation density and the perfection and types of the grain boundaries present.

The aim of this paper was to study the structural and phase transformations taking place during the mechanical alloying of the $\mathrm{Fe}-40$ at \% Al powder mixture in a highenergy ball mill. For this purpose several experimental methods, such as X-ray diffraction (XRD), scanning electron microscopy (SEM), and differential scanning calorimetry (DSC), were used. The obtained results demonstrate that strain broadening caused by high-energy mechanical alloying can be explained by the mechanism of dislocations.

\section{Experimental Data}

Pure elemental powders, $\mathrm{Fe}(99.9 \%)$ and $\mathrm{Al}$ (99.3\%), with, respectively, $80-60$ and $120-80 \mu \mathrm{m}$ particle sizes, were separately weighed and mixed to get the desired composition (Fe40 at $\% \mathrm{Al}$ ). Mechanical alloying was carried out in a vibrator mixed Mill (Fritsch "Pulverisette 9") at room temperature, using agate vials and ball, so that contamination debris, if any, should not be soluble in the powder. Milling proceeds with a constant speed of rotation automatically fixed. In order to reduce the heating by milling, the duration of the process is fixed by an electronic timer and is on a maximum of $15 \mathrm{~min}$.

The microstructural characterizations of the milled powders were carried out with a wide angle diffractometer using Co- $\mathrm{K}_{\alpha}$ radiation $(\lambda=0.1791603 \mathrm{~nm})$. Scans were collected over a $2 \theta$ range of $30-110^{\circ}$ with a step of $0.02^{\circ}$. A 10second acquisition time was used at each step to obtain good statistics.

The experimental Bragg reflections were fitted by the pseudo-Voigt function [16, 17]. The software used was PROFILE-FIT, included in the WinPLOTER graphical tool software package. Therefore, one can get the physical profile of the milled $\mathrm{Fe}(\mathrm{Al})$, which is the convolution of size broadening with strain broadening profile, by removing the instrumental broadening effect from the measured intensity profile. The grain size and the lattice strain of the milled samples can be calculated from the integral width of the physical broadening profile $\beta_{h k l}$ by the Scherrer and Wilson equation [18]:

$$
\frac{\beta_{h k l}^{2}}{t g^{2} \theta_{h k l}}=\frac{\lambda \beta_{h k l}}{D_{h k l} t g \theta_{h k l} \sin \theta_{h k l}}+16\left\langle\varepsilon_{h k l}^{2}\right\rangle^{1 / 2},
$$

where $\lambda$ is the wavelength of Co- $\mathrm{K}_{\alpha}$ irradiation and $D_{h k l}$ and $\left\langle\varepsilon_{h k l}^{2}\right\rangle^{1 / 2}$ represent the thickness and the mean lattice strain of the grains in the $\langle h k l\rangle$ directions, respectively. $\theta_{h k l}$ is the centroid peak position, and $\beta_{h k l}$ is the integral width of the physical broadening profile which is taken as the ratio between the integrated intensity (the area of the peak) $I_{\text {int }}$ and its height $I_{\max }$. By performing a least square fit to $\beta_{h k l}^{2} / \operatorname{tg}^{2} \theta_{h k l}$ plotted against $\lambda \beta_{h k l} / \operatorname{tg} \theta_{h k l} \sin \theta_{h k l}$ for all of the measured peaks of a sample, we are able to determine the mean grain size $D$ and the mean lattice strain $\left\langle\varepsilon_{h k l}^{2}\right\rangle^{1 / 2}$.

The lattice parameter of the powder before and after milling was obtained from a linear regression analysis of the measured lattice parameter, obtained from each peak, plotted against the Nelson-Riley function [19]:

$$
\mathrm{NR}=\cos ^{2} \theta \times\left(\frac{1}{2 \sin \theta}+\frac{1}{2 \theta}\right),
$$

and extrapolated to $\mathrm{NR}=0$; that is, $2 \theta=180^{\circ}$.

The morphology and composition study was followed by scanning electron microscopy (SEM). Thermal behaviour was performed under Ar atmosphere using differential scanning calorimetry (Mettler DSC822e) at a temperature range from 25 to $700^{\circ} \mathrm{C}$ at a constant rate of $20^{\circ} \mathrm{C} / \mathrm{min}$.

\section{Results and Discussion}

3.1. Morphology and Particle Size Analysis. Figure 1 shows SEM images of $\mathrm{Fe}(\mathrm{Al})$ powder particles mechanically alloyed for 2,12 , and $20 \mathrm{~h}$ of milling. In the first stage of the process the powder particles were found to be nearly spherical shaped or at least equiaxed (Figure 1(a)) with an average size of $\sim 50 \mu \mathrm{m}(2 \mathrm{~h})$. In addition, one can see the fracture of these particles (Figure $1\left(a_{1}\right)$ ). After $12 \mathrm{~h}$ of milling the shape of the particles became more regular and almost spherical, and a considerable change in the particle size is observed (Figure $1(b)$ ). Figure $1\left(b_{1}\right)$ shows how small particles are welded to the surface of bigger ones during subsequent milling until the entire particles consist of thin welded layers (Figure 1(c)). Moreover, further milling leads to a matrix of randomly welded thin layers of highly deformed particles. Probably some undeformed fragments of initial powder particles are embedded (Figure 1(c)).

Figure 2 shows the change of the average particle size as a function of milling time. It can be seen that the average particle size changes greatly after the mechanical milling. Three stages, that is, severe plastic deformation (SPD), fracture, and cold welding, can be differentiated depending on milling time. The unmilled powder particles were found to be nearly ellipsoids or spherical shaped. When the milling time is $4 \mathrm{~h}$, the average particle size decreases from 150 to $20 \mu \mathrm{m}$, and the particles were found to be irregular in shape, and flattened, because of the strong plastic deformation occurring accompanied by particle fracture during the first period of the milling (Figure $1\left(a_{1}\right)$ ). Then, for extended milling time (about $8 \mathrm{~h}$ ), cold welding of very small particles to the surface of big particles has occurred, and the average particle size increases from 20 to $70 \mu \mathrm{m}$. Further milling leads to the fracture of the bigger particles, and their shape was 


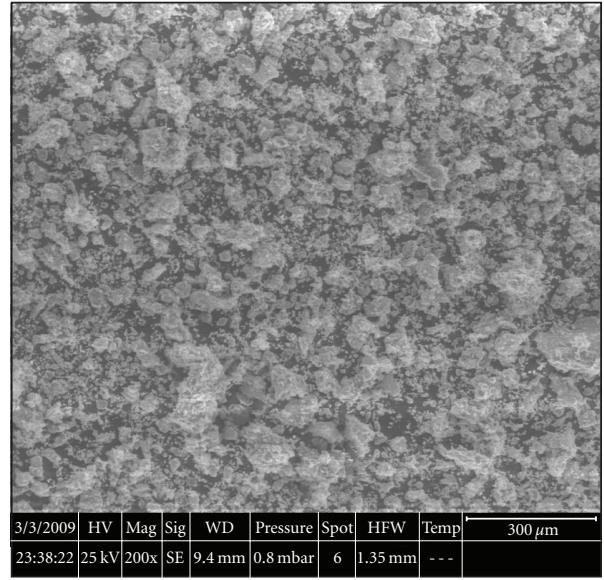

(a)

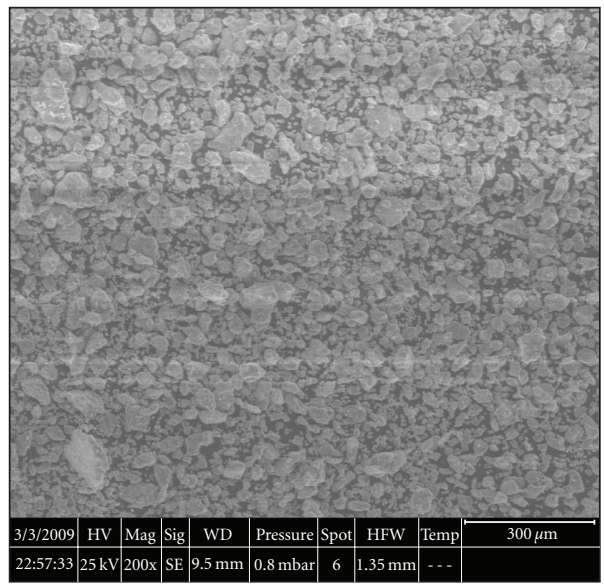

(b)

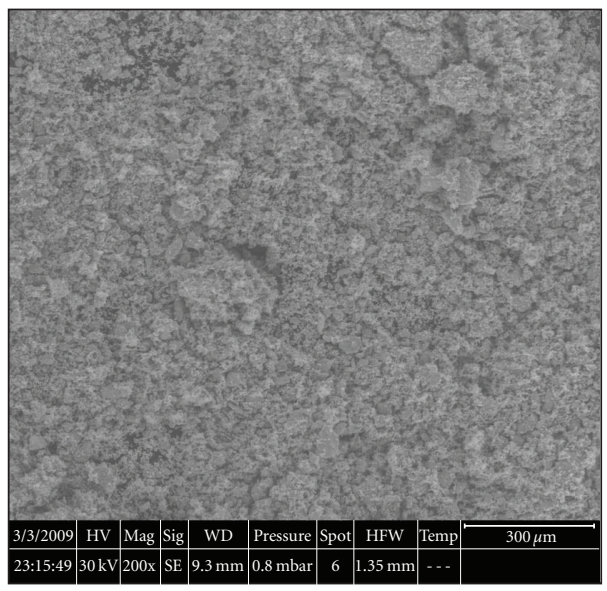

(c)

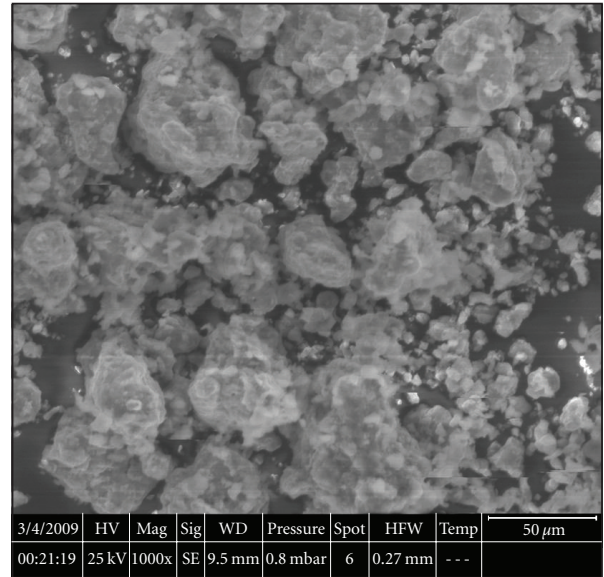

$\left(\mathrm{a}_{1}\right)$

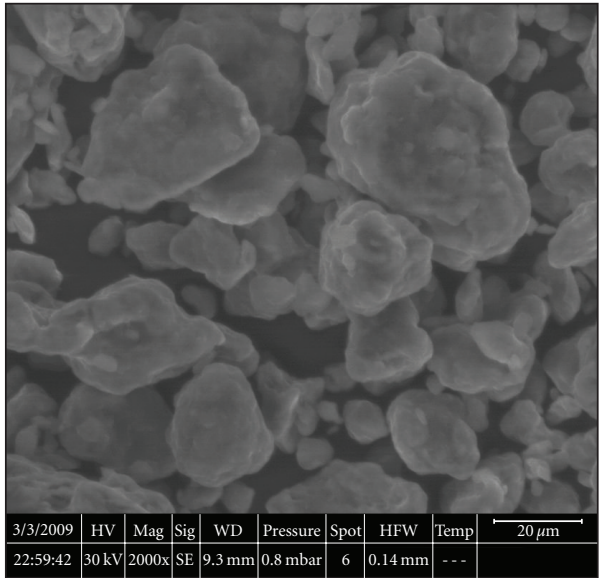

$\left(b_{1}\right)$

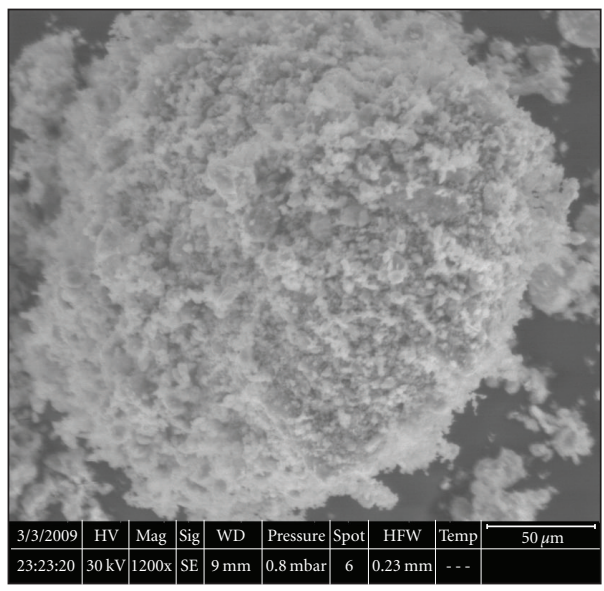

$\left(c_{1}\right)$

Figure 1: SEM images of the Fe(Al) powder particles mechanically alloyed: (a) and ( $\left.a_{1}\right)$ for $2 \mathrm{~h}$, (b) and ( $\left.\mathrm{b}_{1}\right)$ for $12 \mathrm{~h}$, and (c) and ( $\left.\mathrm{c}_{1}\right)$ for $20 \mathrm{~h}$.

found to be nearly spherical. Finally, the fragments are cold welded together, and the fine powder particles are embedded to form a matrix of randomly welded thin layers of highly deformed particles (Figure $1\left(c_{1}\right)$ ). Figure 2 suggests that the size grows with milling times.
3.2. Structural Analysis. Figure 3 shows the XRD patterns for the $\mathrm{Fe}(\mathrm{Al})$ samples after different milling times. The most noticeable features are the transformations occurring in the powder samples during milling. In addition, one can see the decrease of the amplitude and the broadening of 


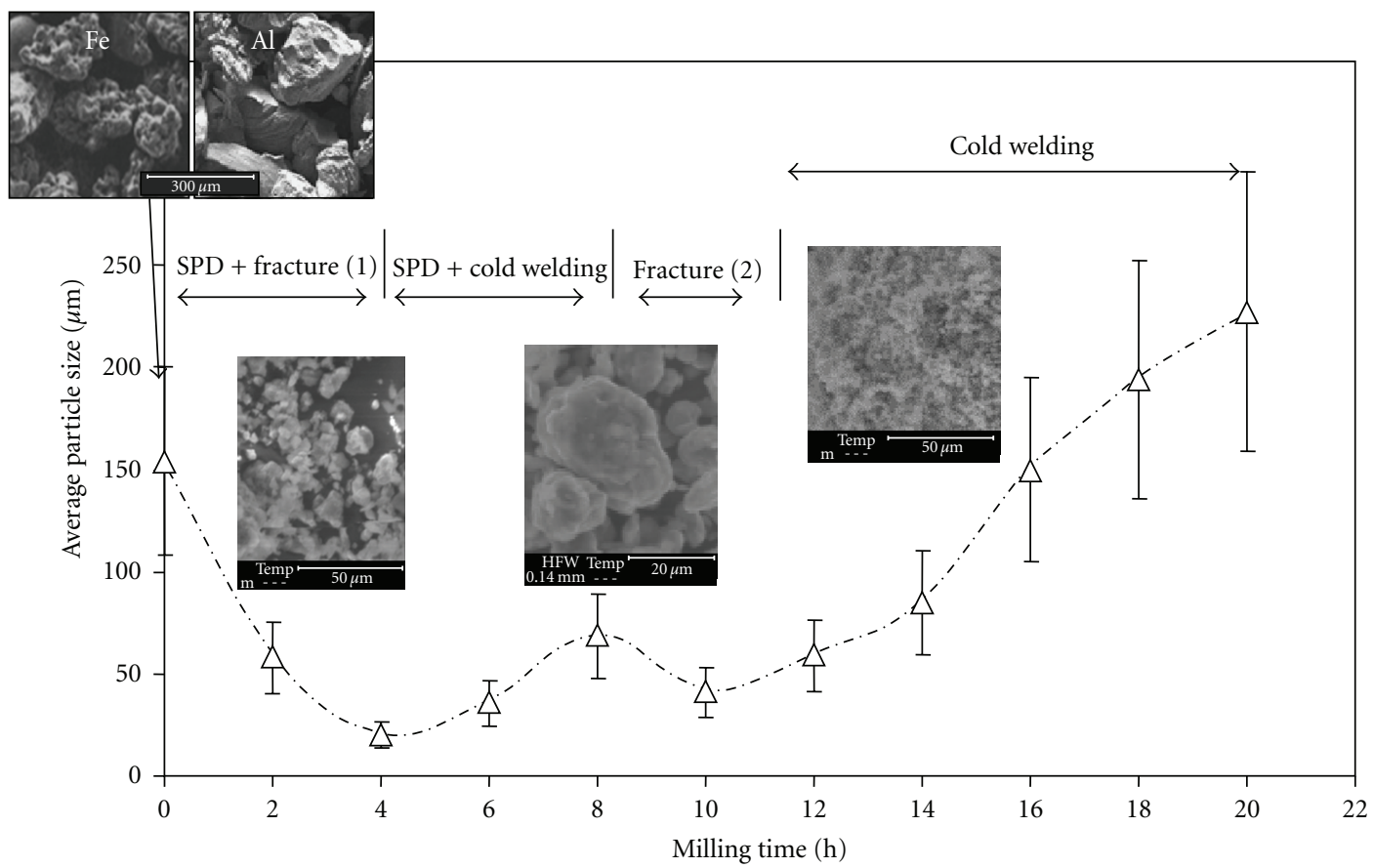

FIGURE 2: Change of particle size with milling time for the $\mathrm{Fe}(\mathrm{Al})$ powder particles mechanically alloyed.

the Bragg peaks with milling time (Figure 3). This is due to the contribution of the effective crystallite size and an increase of the atomic level strain because of heavy plastic deformation. In the milled powders for $2 \mathrm{~h}$, the $\mathrm{Al}(200)$, (220), and (222) peaks overlap with the Fe (110), (200), and (211) peaks, respectively (Figure 3 ). After $12 \mathrm{~h}$ of milling the intensity of the most intense $\mathrm{Al}_{(111)}$ is very low. Moreover, the $(311)_{\mathrm{Al}}$ peak is not present. Therefore, we can assume that the contribution of other relatively less-intense $\mathrm{Al}$ peaks to the intensity of the asymmetric peaks is negligible. This allows us to fit and analyse all the asymmetric peaks in the XRD pattern of the powder mechanically alloyed for $12 \mathrm{~h}$. The result of the fitting procedure is shown in Figure 4(a) for the bcc (211) peak, as an example. The lattice parameters of the $\mathrm{Fe}$ and $\mathrm{Fe}(\mathrm{Al})$ phases calculated using the positions of the fitted peaks (in Figure $4(\mathrm{a})$ ) of each phase are equal to 2.866 and $2.872 \AA$, respectively.

After $14 \mathrm{~h}$ of milling the $(111)_{\mathrm{Al}}$ peak disappears completely (Figure 3 ), whereas the remaining peaks become more symmetric (i.e., the bcc (211) peak represented in Figures 4(b) and 4(c)) and can be related to one $\mathrm{Fe}(\mathrm{Al})$ bcc phase. The XRD patterns of the powders mechanically alloyed for 16,18 , and $20 \mathrm{~h}$ do not differ from the pattern obtained after $14 \mathrm{~h}$ of milling (Figure 3 ).

Figure 5 shows the dependence of the calculated grain size and microstrains on the milling time. The refinement of the microstructure during mechanical alloying is significant, and it is less than $100 \mathrm{~nm}$ after $2 \mathrm{~h}$. It is seen that the average crystallite size decreases exponentially with rapid decrease in the initial hours of milling to reach a nearly constant value of $10 \mathrm{~nm}$ after $10 \mathrm{~h}$ of milling (Figure 5(a)). This might be related to the fact that during MA, the nanometer scaled diffusion couples are produced by high-energy mechanical

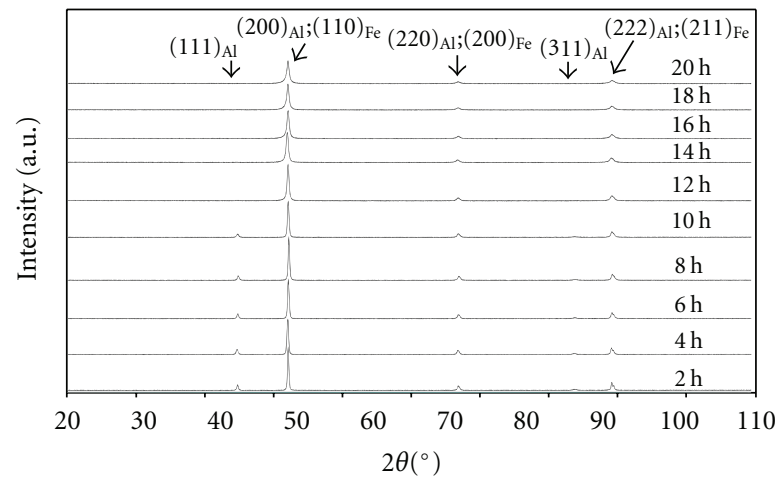

FIGURE 3: X-ray diffraction patterns of mechanically alloyed $\mathrm{Fe}(\mathrm{Al})$ samples as a function of the milling time.

milling which involves plastic deformation, fracture, and cold welding of powder particles. Thus, the atomic diffusivity is enhanced through the creation of a large amount of structural defects. Consequently, metastable phases, such as $\alpha$-Fe(Al) SSS, may well be the first product of the solid state reactions. After 10 hours of milling one can see an increase of the value of the mean crystallite size from 10 (for $10 \mathrm{~h}$ ) to $15 \mathrm{~nm}$ (for 12), then decreases to $8 \mathrm{~nm}$ (for 18 and $20 \mathrm{~h}$ ). This is most probably due to dynamic recrystallization of grains created by local heating during the mechanical alloying process, where the temperature may increase by up to 100 degrees $[9,20]$. Similar behaviour is observed in the case of the microstrain (we note a decrease of lattice strain for $12 \mathrm{~h}$ milling (Figure 5(b))) and can be attributed to strain release. The final grain sizes of the BCC solid solution after $20 \mathrm{~h}$ of milling is about $8 \mathrm{~nm}$. 


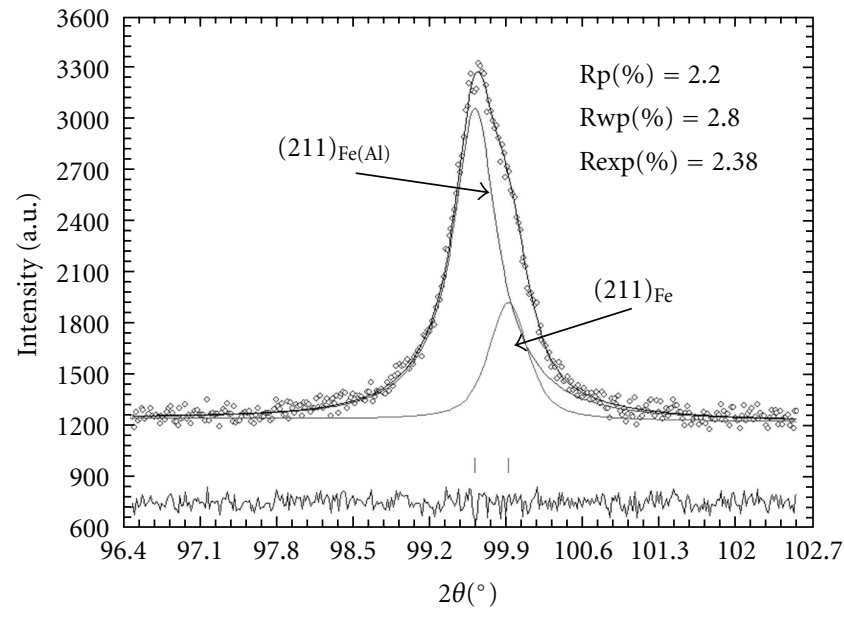

(a)

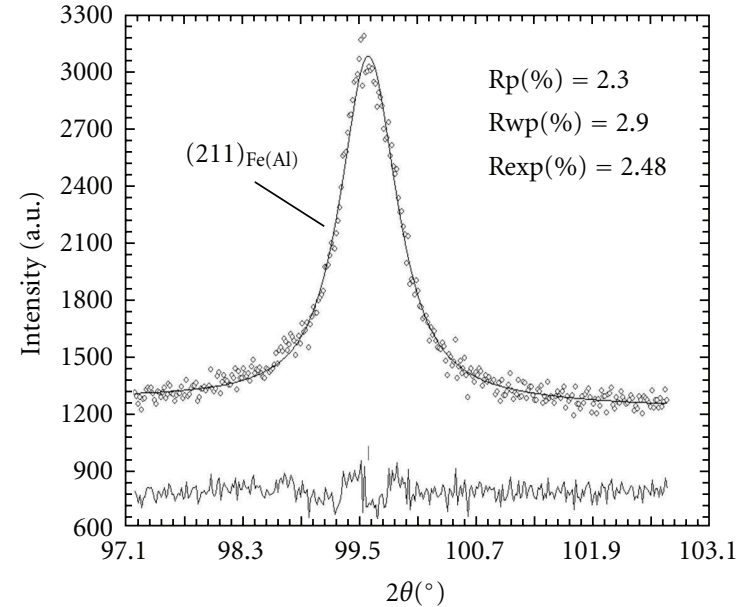

(b)

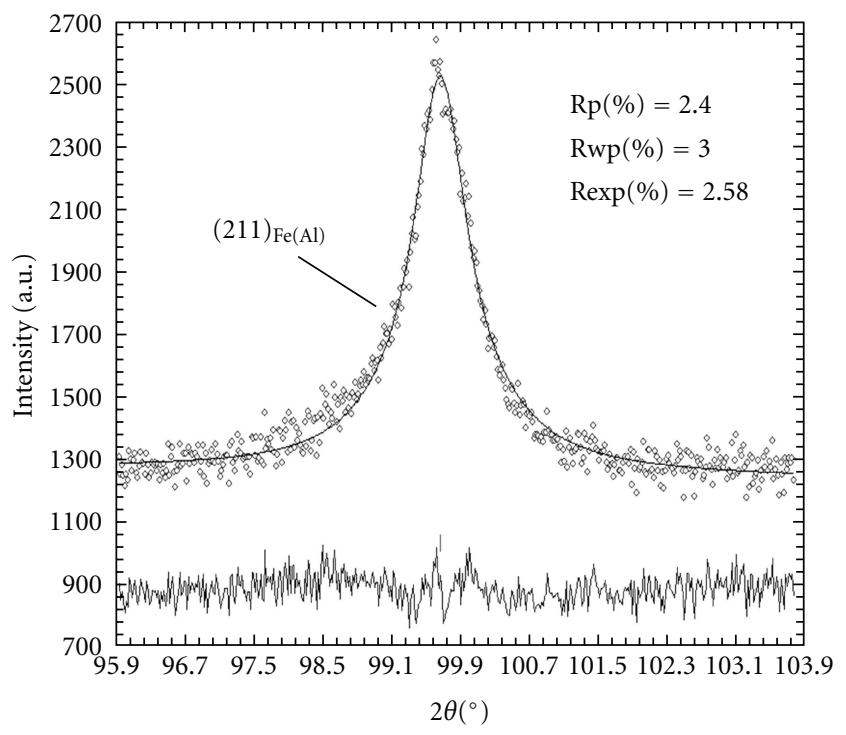

(c)

FIGURe 4: Observed (points) and calculated (solid line) room temperature X-ray diffraction patterns of $(211)_{\mathrm{Fe}}$ and (211) $\mathrm{Fe}(\mathrm{Al}) \mathrm{peaks}$ for (a) $12 \mathrm{~h}$, (b) $14 \mathrm{~h}$, and (c) $20 \mathrm{~h}(\lambda=1.7890100 \AA)$. Positions of the Bragg reflections are represented by vertical bars. The observed-calculated difference pattern is depicted at the bottom of each figure.

This drastic decrease of the grain size corresponds to substantial increase of lattice strain from 0.4 to $1.85 \%$ for 2 and $20 \mathrm{~h}$, respectively, due to plastic deformation generated from the high energy introduced by ball milling. Lattice strain caused by MA is commonly attributed to the generation and movement of dislocations [21]. Fecht [22] claimed that the generation and the movement of dislocations could decrease grain size. Rawers and Cook [23] showed that the strain on the nanograin boundary could extend into nanograin, expanding the lattice. So, for MA samples subjected to severe plastic deformation, dislocations are the main defects, and this dislocation density, $\rho$, can be represented in terms of $D$ and $\left\langle\varepsilon^{2}\right\rangle^{1 / 2}$ by [24-26]:

$$
\rho_{D}=2 \sqrt{3} \frac{\left\langle\varepsilon^{2}\right\rangle^{1 / 2}}{D \times b},
$$

where $b$ is the burgers vector of dislocations and equals $(a \sqrt{3}) / 2$ for the bcc structure. The calculated dislocation densities of the $\mathrm{MA} \mathrm{Fe}(\mathrm{Al})$ samples are represented in Figure 6 . It is clearly seen that $\rho_{D}$ increases from about $0.09 \times$ $10^{16} / \mathrm{m}^{2}$ to $1.85 \times 10^{16} / \mathrm{m}^{2}$ with increasing milling time from 0 to $10 \mathrm{~h}$ and then decreases slightly to $1.4 \times 10^{16} / \mathrm{m}^{2}$. This is most probably due to partial dynamic recrystallization. Usually, in conventional polycrystalline materials, the GBs are thought to be barriers to the dislocations motion; therefore, the slight decrease in the dislocations density within further milling time indicates a softening of the GBs. When the GBs have turned soft or relaxed, the amount of the dislocations piled up near the GBs will be decreased. At further milling time, one can see a drastic increase of $\rho_{D}$ to $2.9 \times 10^{16} / \mathrm{m}^{2}$ and remain unchanged at a steady-state value. By performing a least square fit to $\rho_{D}$ plotted against milling 


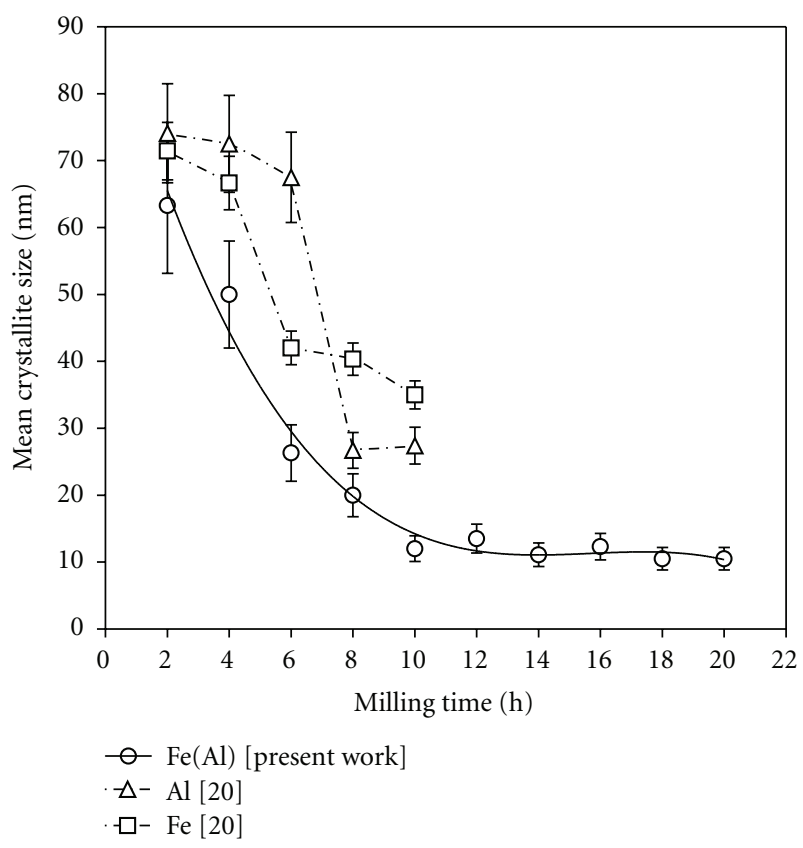

(a)

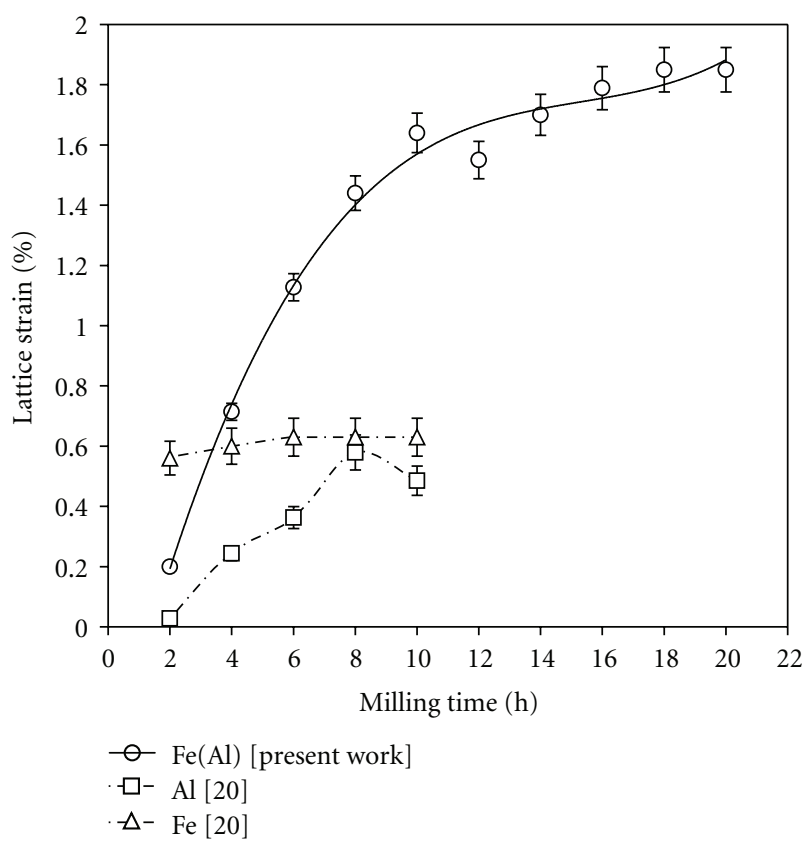

(b)

Figure 5: Milling time dependence of the mean crystallite size (a), $\langle D\rangle$, and the Lattice strain (b), $\left\langle\varepsilon^{2}\right\rangle^{1 / 2}$, for the mechanically alloyed $\mathrm{Fe}(\mathrm{Al})$ powders at room temperature.

time for the two stages, we are able to see an exponential evolution as pointed on Figure 6.

The lattice parameter values of the $\mathrm{Fe}(\mathrm{Al})$ phase calculated as a function of milling time, are given in Figure 7. As can be seen, during the initial period of the milling process, an increase of the lattice parameter of nucleated phase, increasing from 2.885 to $2.908 \AA$. Then, it increases slightly to reach a steady value of $2.915 \AA$.

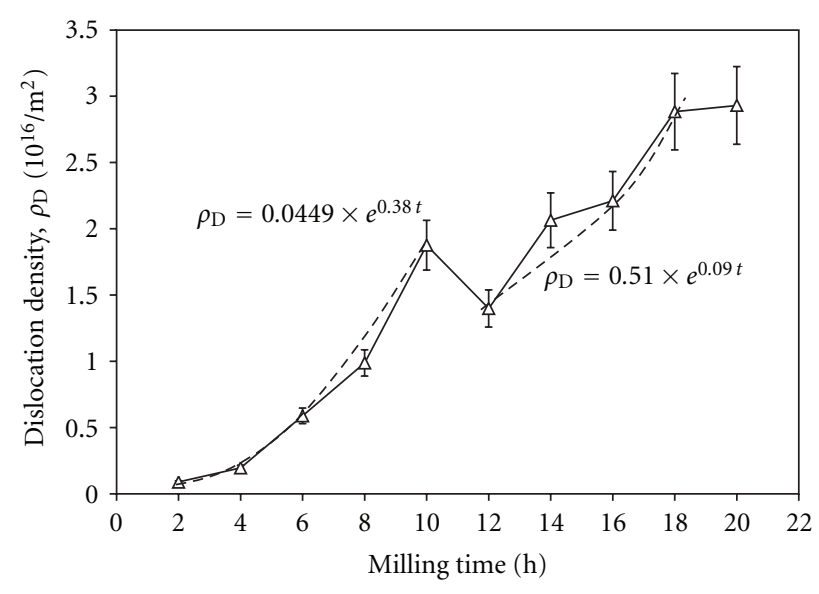

FIGURE 6: Milling time dependence of the mean dislocation density of the mechanically alloyed $\mathrm{FeAl}$ powders.

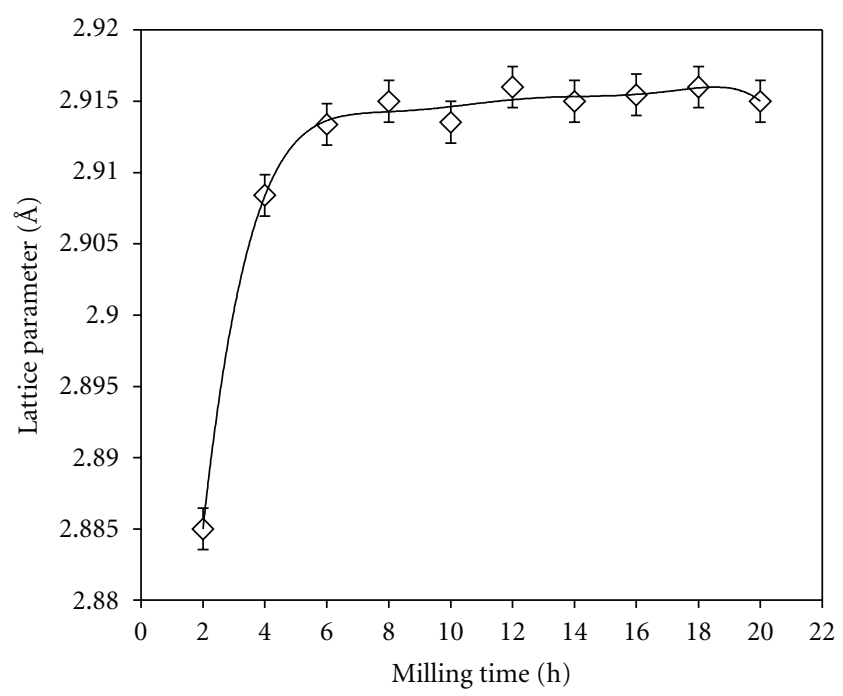

FIGURE 7: Milling time dependence of the mean lattice parameter of the mechanically alloyed FeAl powders.

The $\mathrm{Al}$ atom has a covalent radius close to that of the $\mathrm{Fe}$ atom: $R_{\mathrm{Al}} / R_{\mathrm{Fe}}=1.01$. The increase of the lattice parameter is probably caused by the lattice expansion due to the increase in the density of dislocations with their characteristic strain fields on the nanograin boundary. On the other hand, the steep increase followed by a steady-state saturation value can be related to the accumulated strain hardening of the powder material during longer milling times.

3.3. Thermal Analysis. Figure 8 shows the DSC curves of the powders after 2, 10, 14, and $20 \mathrm{~h}$ of milling. After milling for $2 \mathrm{~h}$, an exothermic peak is observed to start at about $425^{\circ} \mathrm{C}$. This is due to the reaction between $\mathrm{Al}$ and $\mathrm{Fe}$ powders, which are not completely alloyed to form $\mathrm{Fe}(\mathrm{Al})$; the result is consistent with XRD observation. The endothermic peak observed at $655^{\circ} \mathrm{C}$ is attributed to melting of a small quantity of $\mathrm{Al}$ which was not consumed by the reaction. 


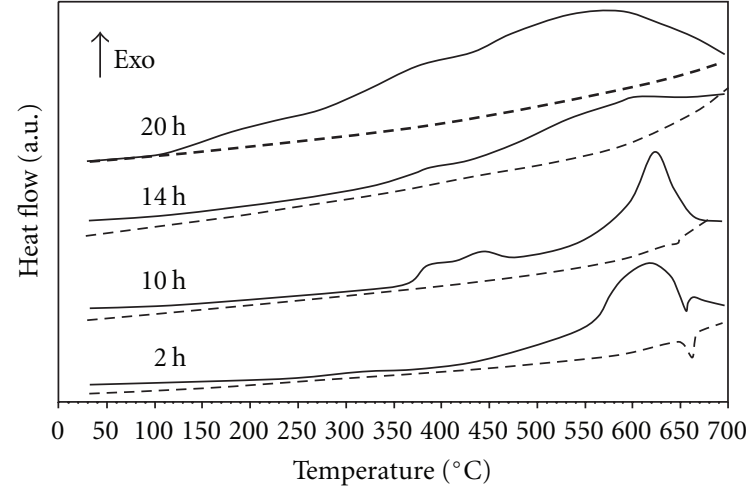

FIGURE 8: DSC curves of the $\mathrm{Fe}(\mathrm{Al})$ powders mechanically alloyed at selected times. Dashed lines are for a second heating cycle.

Three overlapping exothermic peaks are observed at temperature near 375,453 , and $638^{\circ} \mathrm{C}$, respectively, in the case of powder milled for $10 \mathrm{~h}$. The low-temperature peaks with total enthalpy of $109.46 \mathrm{j} / \mathrm{g}$ correspond to the ordering of disordered $\mathrm{Fe}(\mathrm{Al})$ solid solution to form $\mathrm{FeAl}(\mathrm{B} 2)$ intermetallic by mechanisms of atomic-scale interchange and the movement of defects. These two overlapped exothermic peaks have been revealed by Zhu and Iwasaki [27] in MA of ternary Fe-Ti-Al powders. They have considered that these exothermic behaviours are associated with (i) the thermally assisted alloying of elements to form $\mathrm{Fe}(\mathrm{Ti}, \mathrm{Al})$ solid solution and (ii) the ordering of the $\mathrm{Fe}(\mathrm{Ti}, \mathrm{Al})$ solid solutions to form $(\mathrm{Fe}, \mathrm{Ti})_{3} \mathrm{Al}$ intermetallics. These exothermic behaviours have been also investigated by Guilemany et al. [28] in cryomilled Fe-25wt\% Al alloy. They supposed that the peaks at lower temperature (below about $450^{\circ} \mathrm{C}$ ) related to the exothermic effects connected directly with alloying of $\mathrm{Fe}$ and $\mathrm{Al}$ remaining after short milling time, as well as to the ordering and forming the FeAl phase. With increased milling time (14 and $20 \mathrm{~h}$ milling), these peaks become weaker and indistinguishable since the Fe and $\mathrm{Al}$ have been completely alloyed to form disordered $\mathrm{Fe}(\mathrm{Al})$, which is also consistent with the XRD data. The total enthalpy of these exothermic effects is about 7 and $4 \mathrm{j} / \mathrm{g}$ for the powders milled for 14 and $20 \mathrm{~h}$, respectively, so it decreases with milling time. The examination of the second heating curve reveals once more the presence of a weaker endothermic peak for the powders milled for $10 \mathrm{~h}$, attributed to the fusion reaction of a small quantity of $\mathrm{Al}$ which is not yet incorporated into $\mathrm{Fe}(\mathrm{Al})$ solid solution. This peak disappears for the powders milled after 14 and $20 \mathrm{~h}$ of milling. According to Zhu and Iwasaki [27], the former mechanism would be dominant for powders milled for shorter times, and the ordering of the solid solutions to form intermetallics would be dominant for powders milled for longer time. On the other hand, Zeng and Baker [9] supposed that the peaks at lower temperature (for longer times) related to the exothermic effects could be associated with short-range ordering and/or vacancies annealing out. Note that, for the milled powder, the formation of solid solutions by the thermally assisted alloying of elements and the formation of the intermetallics by the disorderorder transformation of solid solution probably proceed through a vacancy migration mechanism [27-29], which depends on the local internal strain, which could enhance the vacancy migration process, thus promoting the formation of solutions or intermetallics. This hypothesis can probably explain the decrease of the intensities of the two overlapped exothermic peaks with milling time as observed in Figure 8.

The peaks at higher temperatures (above about $450^{\circ} \mathrm{C}$ ) are probably related to the recrystallization and grain growth in the FeAl intermetallics. The total enthalpy of the exothermic effects is about 530, 528, and $533 \mathrm{j} / \mathrm{g}$ for the powders milled for 10, 14, and $20 \mathrm{~h}$. However, Morris-Muñoz et al. adapted this analysis of DSC results to mechanical alloying of elemental Fe-Al powders [30]. They supposed that higher temperatures will be required for complete loss of the defects produced by milling and for grain growth. Very high temperatures are required, nevertheless, to remove essentially all the internal strain. The crystal size increases steadily with annealing temperature, and it is only at $900^{\circ} \mathrm{C}$ and above that grain growth becomes excessive [30].

\section{Conclusion}

The nanostructured $\mathrm{Fe}(\mathrm{Al})$ solid solution is successfully synthesized from the mixture of elemental $\mathrm{Fe}$ and $\mathrm{Al}$ powders in an atomic ratio of $60 / 40$ by mechanical alloying. The phase changes of the powder mixture during mechanical alloying are investigated. At the early stage of the process, $\mathrm{Fe}(\mathrm{Al})$ solid solution is formed firstly by the solution of $\mathrm{Al}$ atoms into BCC Fe lattice; we note that the increase in milling, time favours the disappearance of the Al melting peak. The single phase of disordered $\mathrm{Fe}(\mathrm{Al})$ was formed after $14 \mathrm{~h}$ of milling and the resulting powder has a nanometer scale structure, with an average crystallite size about $8 \mathrm{~nm}$ and a dislocation density of $2.9 \times 10^{16} / \mathrm{m}^{2}$.

\section{Acknowledgments}

Financial support from MICYT MAT2006-13925-C02-02 (FEDER) project is acknowledged. The authors express their gratitude to Mr. Xavier Fontrodona (Serveis Tècnics de Recerca, Universitat de of Girona) for collaboration.

\section{References}

[1] A. R. Yavari, P. J. Desré, and T. Benameur, "Mechanically driven alloying of immiscible elements," Physical Review Letters, vol. 68, no. 14, pp. 2235-2238, 1992.

[2] J. Kuyama, H. Inui, S. Imaoka, S. Nasu, K. N. Ishihara, and P. H. Shingu, "Nanometer-sized crystals formed by the mechanical alloying in the Ag-Fe system," Japanese Journal of Applied Physics, vol. 30, pp. L854-L856, 1991.

[3] K. Uenishi, K. F. Kobayashi, K. N. Ishihara, and P. H. Shingu, "Formation of a super-saturated solid solution in the $\mathrm{AgCu}$ system by mechanical alloying," Materials Science and Engineering A, vol. 134, pp. 1342-1345, 1991.

[4] E. P. Yelsukov and G. A. Dorofeev, "Mechanical alloying in binary Fe-M ( $\mathrm{M}=\mathrm{C}, \mathrm{B}, \mathrm{Al}, \mathrm{Si}, \mathrm{Ge}, \mathrm{Sn})$ systems," Journal of Materials Science, vol. 39, no. 16-17, pp. 5071-5079, 2004. 
[5] D. Oleszak and P. H. Shingu, "Mechanical alloying in the FeAl system," Materials Science and Engineering A, vol. 181-182, pp. 1217-1221, 1994.

[6] S. Enzo, R. Frattini, R. Gupta et al., "X-ray powder diffraction and Mössbauer study of nanocrystalline Fe-Al prepared by mechanical alloying," Acta Materialia, vol. 44, no. 8, pp. 31053113, 1996.

[7] S. Enzo, G. Mulas, and R. Frattini, "The structure of mechanically alloyed AlFe end-products after annealing," Materials Science Forum, vol. 385, no. 1, pp. 269-272, 1998.

[8] S. Enzo, R. Frattini, G. Mulas, and F. Delogu, "Structural evolution of AlFe and AlFe powders prepared by mechanical alloying," Materials Science Forum, vol. 391, no. 1, pp. 269 272, 1998.

[9] Q. Zeng and I. Baker, "Magnetic properties and thermal ordering of mechanically alloyed $\mathrm{Fe}-40 \mathrm{at} \% \mathrm{Al}$," Intermetallics, vol. 14, no. 4, pp. 396-405, 2006.

[10] R. A. Varin, J. Bystrzycki, and A. Calka, "Characterization of nanocrystalline $\mathrm{Fe}-45$ at\% $\mathrm{Al}$ intermetallic powders obtained by controlled ball milling and the influence of annealing," Intermetallics, vol. 7, no. 8, pp. 917-930, 1999.

[11] K. Wolski, G. Le Caër, P. Delcroix, R. Fillit, F. Thévenot, and J. Le Coze, "Influence of milling conditions on the FeAl intermetallic formation by mechanical alloying," Materials Science and Engineering A, vol. 207, no. 1, pp. 97-104, 1996.

[12] S. H. E. Haghighi, K. Janghorban, and S. Izadi, "Structural evolution of $\mathrm{Fe}-50$ at.\% Al powders during mechanical alloying and subsequent annealing processes," Journal of Alloys and Compounds, vol. 495, no. 1, pp. 260-264, 2010.

[13] M. Krasnowski, A. Grabias, and T. Kulik, "Phase transformations during mechanical alloying of Fe-50\% $\mathrm{Al}$ and subsequent heating of the milling product," Journal of Alloys and Compounds, vol. 424, no. 1-2, pp. 119-127, 2006.

[14] S. Suriñach, S. Gialanella, X. Amils, L. Lutterotti, and M. D. Baró, "Thermoanalytical characterization of a nanograined Fe-40Al alloy," Materials Science Forum, vol. 225, no. 1, pp. 227-395, 1996.

[15] S. Gialanella, X. Amils, M. D. Barò et al., "Microstructural and kinetic aspects of the transformations induced in a FeAl alloy by ball-milling and thermal treatments," Acta Materialia, vol. 46, no. 9, pp. 3305-3316, 1998.

[16] B. H. Armstrong, "Spectrum line profiles: the Voigt unction," Journal of Quantitative Spectroscopy and Radiative Transfer, vol. 7, no. 1, pp. 61-88, 1967.

[17] J. I. Langford, R. Delhez, TH. H. de Keijser, and E. J. Mittemeijer, "Profile analysis for microcrystalline properties by the Fourier and other methods," Australian Journal of Physics, vol. 41, no. 2, pp. 173-187, 1988.

[18] H. P. Klug and L. E. Alexander, X-Ray Diffraction Procedures of Polycrystalline and Amorphous Materials, chapter 9, John Wiley \& Sons, New York, NY, USA, 2nd edition, 1974.

[19] L. V. Azàroff and M. Buerger, The Powder Method, McGrawHill, New York, NY, USA, 1958.

[20] R. M. Davis, B. McDermott, and C. C. Koch, "Mechanical alloying of brittle materials," Metallurgical Transactions A, vol. 19, no. 12, pp. 2867-2874, 1988.

[21] F. A. Mohamed, "A dislocation model for the minimum grain size obtainable by milling," Acta Materialia, vol. 51, no. 14, pp. 4107-4119, 2003.

[22] H.-J. Fecht, "Nanostructure formation by mechanical attrition," Nanostructured Materials, vol. 6, no. 1-4, pp. 33-42, 1995.
[23] J. Rawers and D. Cook, "Influence of attrition milling on nano-grain boundaries," Nanostructured Materials, vol. 11, no. 3, pp. 331-342, 1999.

[24] G. K. Williamson and R. E. Smallman, "Dislocation densities in some annealed and cold-worked metals from measurements on the X-ray debye-scherrer spectrum," Philosophical Magazine, vol. 1, no. 1, pp. 34-46, 1956.

[25] R. E. Smallman and K. H. Westmacott, "Stacking faults in facecentred cubic metals and alloys," Philosophical Magazine, vol. 2, no. 17, pp. 669-683, 1957.

[26] Y. H. Zhao, H. W. Shang, and K. Lu, "Microstructure evolution and thermal properties in nanocrystalline Fe during mechanical attrition," Acta Materialia, vol. 49, pp. 365-375, 2001.

[27] S.U. M. Zhu and K. Iwasaki, "Characterization of mechanically alloyed ternary Fe-Ti-Al powders," Materials Science and Engineering A, vol. 270, no. 2, pp. 170-177, 1999.

[28] J. M. Guilemany, N. Cinca, L. Casas, and E. Molins, “Ordering and disordering processes in MA and MM intermetallic iron aluminide powders," Journal of Materials Science, vol. 44, no. 8, pp. 2152-2161, 2009.

[29] F. Cardellini, F. Cleri, G. Mazzone, A. Montone, and V. Rosato, "Experimental and theoretical investigation of the order-disorder transformation in NiAl," Journal of Materials Research, vol. 8, no. 10, pp. 2504-2509, 1993.

[30] M. A. Morris-Muñoz, A. Dodge, and D. G. Morris, "Structure, strength and toughness of nanocrystalline FeAl," Nanostructured Materials, vol. 11, no. 7, pp. 873-885, 1999. 

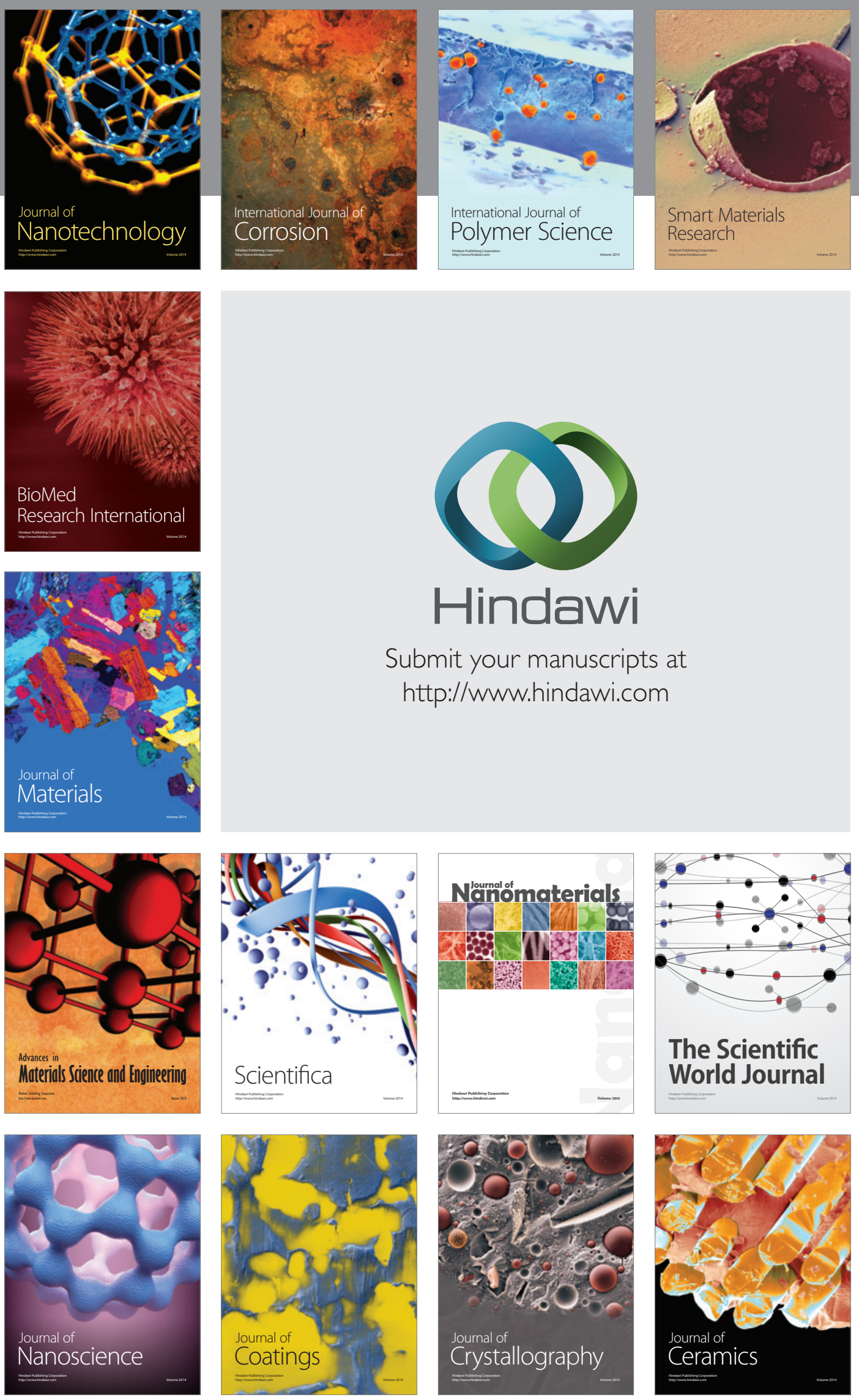

The Scientific World Journal

Submit your manuscripts at

http://www.hindawi.com

\section{World Journal}

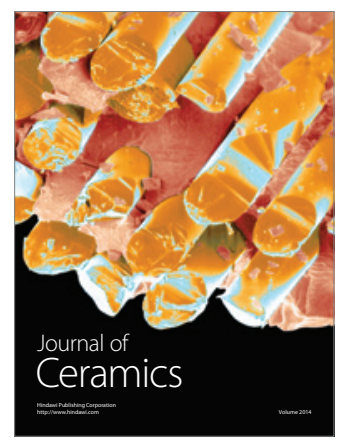

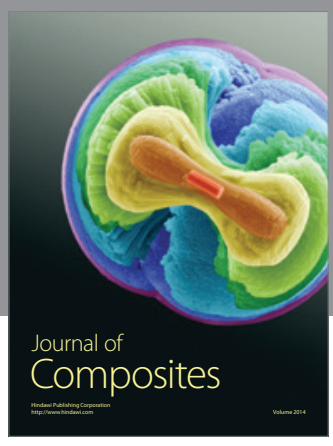
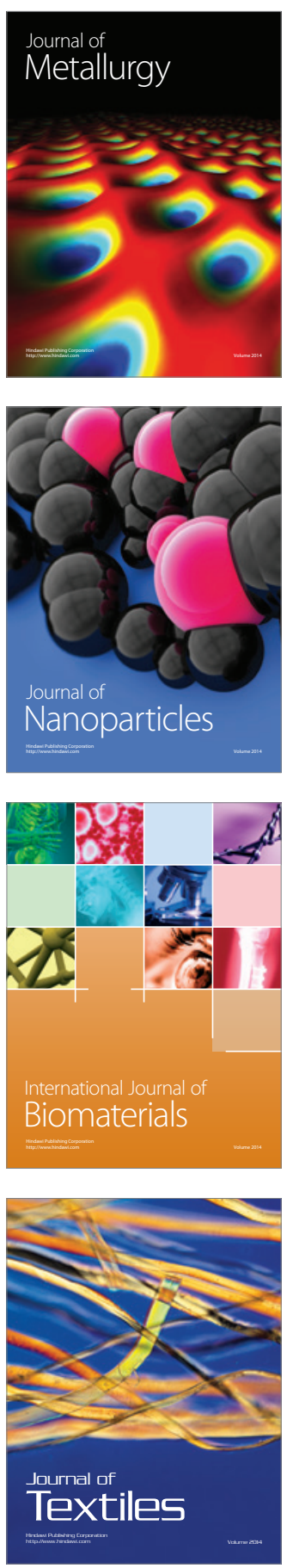